\title{
REPRESENTAÇÕES DO CONSERVADORISMO CONTEMPORÂNEO: O PENSAMENTO POLÍTICO DE ANTÔNIO FERREIRA PAIM
}

\author{
Representations of contemporary conservatism: the political thought of Antônio \\ Ferreira Paim
}

José Wilson Assis Neves Júnior ${ }^{1}$

\begin{abstract}
RESUMO: Este artigo teve o objetivo de analisar o pensamento político do filósofo brasileiro Antônio Ferreira Paim, enquanto um dos principais representantes contemporâneos do pensamento conservador brasileiro. Foram intencionalmente selecionadas três obras do autor, sendo elas: As Filosofias Nacionais, Momentos Decisivos na História do Brasil e Liberdade Acadêmica e Opção Totalitária. As fontes foram abordadas pelo método materialista histórico-dialético de matriz lukácsiana, visando, assim, apreender ontologicamente o cerne político-ideológico de suas formulações filosóficas. $\mathrm{O}$ trabalho se encontra dividido em três momentos, a classificação do posicionamento de classe assumido pelo autor frente à realidade nacional, a análise da forma como Paim compreende o processo de transformação social (a partir da dinâmica de mudança que decorre das relações entre infraestrutura e superestrutura) e a identificação do projeto de porvir que fundamenta suas formulações filosóficas. A pesquisa identificou a forma como sua perspectiva liberal culturalista flerta, em vários momentos, com correntes positivistas e tradicionalistas (especialmente no que tange ao catolicismo). Destacou-se, ainda, a propensão do autor em recorrer ao racionalismo formal como método para elencar elementos específicos de conjunturas históricas para defender suas pretensões político-ideológicas. Por fim, indica-se o projeto de porvir de um modelo político-econômica pautado nas privatizações neoliberais e no pluralismo político controlado.
\end{abstract}

PALAVRAS-CHAVE: Pensamento Político Brasileiro; Conservadorismo; Política Contemporânea; Ideologias.

ABSTRACT: This paper aimed to analyze the political thought of the Brazilian philosopher Antônio Ferreira Paim, as one of the main representatives of brazilian's contemporary conservative thought. Three works of the author were intentionally selected: The National Philosophies, Decisive Moments in the History of Brazil and Academic Freedom and Totalitarian Option. The research sources were approached by the lukácsian's matrix of materialism historic-dialectical method, thus aiming to ontologically apprehend the political-ideologic core of his philosophical formulations. The paper is divided in three moments, the classification of the class position assumed by the author in front of national reality, the analysis of the way that Paim comprehends the social transformation process (from the changing dynamic that accrue of the relations between infrastructure and superstructure) and the identification of the "for coming" project that grounds his philosophical formulations. The research identified the way that his culturalist liberal perspective flirts, in several moments, with currents of positivism and traditionalism (especially Catholicism). Stood out, also, the author's propensity to resort to formal rationalism as method for list specific elements from historical conjunctures to defend his political-ideologic pretensions. Ultimately, it's indicated the "for coming" project of a political-economic model linked to neoliberal privatization and a controlled political pluralism.

KEY-WORDS: Brazilian Political Thought; Conservatism; Contemporary Politics; Ideology.

\footnotetext{
${ }^{1}$ Doutorando pelo Programa de Pós-Graduação em Ciências Sociais da Universidade Estadual Paulista (Unesp/Marília). Bolsista Capes. Mestre e bacharel em Ciências Sociais pela Universidade Estadual de Londrina. "Pesquisador vinculado ao Grupo de Pesquisa Pensamento Político Brasileiro e LatinoAmericano (Unesp/Marília). E-mail: nevesjr1991@ gmail.com"
} 


\section{Introdução}

Este trabalho visa analisar o pensamento político do filósofo baiano Antônio Ferreira Paim, considerado enquanto um dos principais intelectuais responsáveis pela formação político-ideológica do conservadorismo brasileiro contemporâneo ressaltando a preocupação da presente pesquisa no que tange aos recentes processos de fortalecimento dos grupos políticos portadores de proposições de extrema-direita tanto em nível nacional quanto internacional (LÖWY, 2015).

Nascido em Jacobina-BA, no dia 07 de maio de 1927, Antônio Ferreira Paim formou-se em filosofia pela Universidade de Brasília e iniciou sua carreira política militando pelo Partido Comunista Brasileiro (PCB), fato que o levou a cursar sua pósgraduação na Universidade Estadual de Moscovo (Rússia). Segundo Czajka (2009), Paim manteve-se vinculado ao PCB durante os anos de 1946 a 1956 e, após sua desvinculação, passou a atuar como jornalista periódico no jornal Correio da Manhã, ingressando em seguida (1959) no Instituto Superior de Estudos Brasileiros (ISEB).

Após o curto período de militância no PCB, a carreira intelectual de Antônio Paim sofreu uma guinada para o liberalismo, passando a posicionar-se criticamente em relação ao marxismo, estabelecendo como principal enfoque de suas pesquisas o pensamento político e filosófico brasileiro, ambicionando compreender as raízes que delinearam o estado atual do pensamento nacional para propor diretrizes de continuidade que possibilitassem o surgimento de uma filosofia realmente brasileira entre as figuras políticas influenciadas pelas ideias de Paim, destaca-se Ricardo Vélez Rodríguez, ${ }^{2}$ ministro da Educação pelo governo de Jair Messias Bolsonaro durante os meses de janeiro à abril de 2019.

Problematiza-se, portanto, o modo como as formulações filosófico-ideológicas de Paim perpassa o direcionamento das decisões políticas brasileiras atuais e como estas se refletem diretamente no âmbito dos conflitos de classe característicos da realidade nacional, atentando-se à particularidade das relações político-econômicas que definem o capitalismo brasileiro. Para tanto, são apropriadas as diretrizes teórico-metodológicas do

\footnotetext{
${ }^{2}$ Indicado para o cargo do Ministério da Educação por Olavo de Carvalho (outro intelectual da extremadireita contemporânea que teve suas raízes políticas do PCB), Ricardo Vélez Rodríguez, pautou seu discurso em proposições anticomunistas, enfatizando uma suposta infiltração marxista no sistema de ensino brasileiro que estaria sendo encabeçada pela CAPES e CNPq desde a ditadura militar brasileira (1964-85). O curto período em que ocupou o Ministério encerrou-se com sua demissão em decorrência da "falta de expertise e gestão".
} 
materialismo histórico-dialético proposto pela leitura marxiana de Georg Lukács (1970; 1981; 2018), especialmente em suas contribuições para a análise das formações filosófico-ideológicas, entendidas enquanto pôr teleológico secundário ${ }^{3}$ que objetiva dirimir os conflitos sociais (LUKÁCS, 2018).

Deste modo, o que se torna relevante no processo de análise do pensamento aqui proposto, é a identificação do posicionamento de classe que Antônio Paim assume para si (considerando a complexidade das relações que perpassam o antagonismo de classes e as configurações especificas e contextuais que caracterizam os grupos de classe de uma realidade social), classificando as pretensões de função social que permeiam suas formulações filosóficas de modo a constituir um sentido de porvir que solucione os problemas imediatos dos conflitos de classe. ${ }^{4}$ Assim, ressalta-se que:

\begin{abstract}
A irreconciliabilidade factual das ideologias que lutando uma contra a outra assimilando, no curso da história, formas as mais diferentes, pode aparecer como interpretação de tradições, de convicções religiosas, de teorias e métodos científicos e assim por diante, todavia, são sempre, antes de tudo, meio de luta; para elas, a questão decisiva é sempre um "o que fazer?"; os meios de justificação dessa pretensão na direção da práxis social permanecem meios cujos métodos, qualidade etc. sempre depende do hic et nunc social da espécie de luta, da espécie de "o que fazer?" nele (LUKÁCS, 2018, p. 399).
\end{abstract}

Desta forma, enfatiza-se que o objetivo principal do presente trabalho consiste na identificação do modo como, filosófico-ideologicamente, Antônio Ferreira Paim posiciona-se frente aos conflitos sociais que se delinearam, sócio-históricamente, na sociedade brasileira, apreendendo, assim, o sentido de suas proposições do porvir e as implicações disto para o processo de resolução dos mencionados conflitos.

As obras de Antônio Paim que são abordadas nesta pesquisa foram selecionadas de forma intencional, de modo que possibilitassem o recorte específico de análise proposto, são elas: As Filosofias Nacionais $(2007)^{5}$, escolhida para identificar o posicionamento de Paim frente aos conflitos de classe em nível filosófico-ideológico; Momentos Decisivos da História do Brasil (2000), escolhida para apreender a

\footnotetext{
${ }^{3}$ De acordo com a perspectiva ontológica lukácsiana o pôr teleológico secundário é aquele que representa a forma como a humanidade desenvolve ideias que possibilitem a articulação social dos indivíduos em prol do direcionamento das ações referentes à divisão social do trabalho - garantindo, assim, a reprodução da relação da humanidade com a natureza (pôr teleológico primário).

${ }^{4}$ Lukács (2018) entende que este posicionamento frente às configurações imediatas do conflito de classes pode potencializar diferentes formas de solução, que vão desde o reacionarismo até a emancipação revolucionária.

${ }^{5}$ Foi selecionada a terceira edição, revisada e ampliada, de forma a apreender com maior profundidade as ideias do autor em relação à contemporaneidade.
} 
compreensão deste intelectual a respeito das relações entre causalidades e objetividades no direcionamento das processos de transformação sócio-históricas; e, por fim, os seus três capítulos de contribuição para a obra Liberdade Acadêmica e Opção Totalitária (1979), que possibilitam compreender o posicionamento do intelectual em relação ao porvir, ou seja, seu posicionamento propositivo de futuro para o direcionamento em prol da resolução dos conflitos de classe.

\section{As filosofias, seus elementos ideológicos e o antagonismo de classes}

Publicada originalmente em 1997, a obra As Filosofias Nacionais foi revisada e reformulada por Antônio F. Paim para publicação de sua terceira edição no ano de 2007 - edição escolhida para análise neste trabalho. Esta obra em específico, constitui-se enquanto um esforço do filósofo baiano em revisar o processo de construção das filosofias nacionais nos Estados Unidos da América e em Portugal, estabelecendo diálogos com as formas como se relacionaram com as filosofias alemãs, inglesas e francesas de modo a propor um redirecionamento para a construção de uma moderna filosofia luso-brasileira.

A partir dos posicionamentos tomados por Antônio Paim (não só em relação as correntes filosóficas herdadas como também a sua proposição de correntes viáveis para a continuidade do processo de desenvolvimento de uma filosofia legitimamente lusobrasileira), torna-se possível identificar a forma como este intelectual se articula político-ideologicamente no que tange aos conflitos de classe. Visa-se, assim, apreender a função social que perpassa o cerne de sua construção filosófico-ideológica.

Já na introdução desta obra, o filósofo baiano traz algumas pistas da forma como sua proposição de análise das correntes teóricas se distingue ou converge com as demais proposições conservadoras de análise do pensamento. Segundo o autor:

A conceituação de filosofia nacional que efetivamos desemboca na necessidade de proceder-se ao confronto entre filosofias nacionais, porquanto não há outra hipótese. Basta tomar um exemplo da moda: o marxismo. Este foi afeiçoado a umas poucas tradições culturais, a russa, a italiana, a francesa, a alemã e a luso-brasileira, produzindo cada uma interpretação inteiramente diversa. Escolher uma delas é tornar-se caudatário dessa ou daquela tradição nacional. A universalidade da filosofia transcrita em outro plano e por isto toda a filosofia nacional autêntica, isto é, conscientemente estruturada em torno de determinados problemas, por isto mesmo é autenticamente universal, como nos ensina António Braz Teixeira. 
A relação entre as filosofias nacionais não pode, portanto, ser a do estabelecimento de subordinações hierárquicas, mas da busca de um diálogo verdadeiro (PAIM, 2007, p. 18-19).

Relevante se faz notar uma característica peculiar na percepção que Antônio F; Paim expressa sobre a construção dos sistemas filosófico-ideológicos nacionais principalmente quando comparada com outros proeminentes teóricos do conservadorismo brasileiro. Para Paim (2007), teorias filosóficas externas são recorrentemente apropriadas no processo de construção das filosofias nacionais, sendo reformuladas de modo a adequar-se à realidade imposta e, primordialmente, aos direcionamentos que especificam os objetos de cada uma destas filosofias em particular.

Assim, diferente de outros teóricos do conservadorismo nacional ${ }^{6}$ o filosofo baiano não trata do marxismo como uma ideologia alienígena, exportada por países comunistas como ferramenta de corrosão das sociedades ocidentais, cristãs e democráticas, mas, sim como vertente de pensamento submetida à transformações e adaptações para as realidades nacionais nas quais é transmitida. Este pode ser entendido como um dos elementos que caracterizam as especificidades de sua perspectiva culturalista de vertente liberal - que será explorada no decorrer das análises.

Existe, portanto, na percepção de Paim um reconhecimento das relações que perpassam o universal e o particular no processo de construção filosófico-ideológico, apesar dos limites que sua perspectiva conservadora e sua opção de classe impõe para a compreensão das reais dimensões deste processo. Esta limitação torna-se expressiva em sua análise sobre a forma como o pensamento político de cunho positivista se construiu na sociedade brasileira.

Retomando o protagonismo de figuras históricas no direcionamento da construção da proposta de Estado Nação do Brasil (com destaque para cientificismo promovido pelo português Marquês de Pombal, ${ }^{7}$ e o positivismo do militar brasileiro

\footnotetext{
6 Dos quais podem-se elencar como proeminentes representantes de suas vertentes do período: o positivista Golbery do Couto e Silva (militar idealizador do Serviço Nacional de Informações e um dos articuladores da própria ditadura militar brasileira) e o tradicionalista Plínio Corrêa de Oliveira (líder da organização católica Tradição Família e Propriedade).

7 Sebastião José de Carvalho Melo (1699-1782), vulgo Marquês de Pombal, foi um dos principais representantes do despotismo esclarecido, protagonizando reformas administrativas, econômicas e sociais em nome da coroa Portuguesa, as quais ficaram conhecidas como Reformas Pombalinas. Apesar das tendências progressistas em relação à ciência, "A modernização realizada por Pombal não compreendia a reforma das instituições políticas. Estas continuaram adstritas ao absolutismo monárquico. Preservou-se a Inquisição, já agora para enquadrar oponentes às reformas. Continua sendo admitido o emprego da tortura" (PAIM, 2000, p. 104-105).
} 
Benjamin Constant Botelho de Magalhães ${ }^{8}$ ) e tomando posicionamento em favor do positivismo, o filósofo baiano (PAIM, 2007, p. 26-28), critica a predominância das ideias tradicionalistas cristãs (principalmente de Joaquim de Fiori ${ }^{9}$ ) não só na formação do pensamento nacional como também na sua atuação em deturpação para adequação das ideias positivistas para a realidade brasileira - no decorrer de suas análises, Paim (2007) também indicará os efeitos nocivos herdados do positivismo para o desenvolvimento político da sociedade brasileira. ${ }^{10}$ Em suas palavras:

[...] a popularidade de que desfruta no Brasil a crença na onipotência do Estado e o correlato amesquinhamento do indivíduo frente àquele crença que se traduz na aceitação dos ideais socialistas, idade de ouro que tem muito a ver com a proposta joaquinista, do mesmo modo que nas dificuldades opostas ao desenvolvimento do capitalismo [...] (PAIM, 2007, p. 28).

A citação expõe os limites de Paim na compreensão da complexidade que decorre dos processos entre singular, particular e universal em sua correlação no trânsito de ideias entre centros e periferias. $\mathrm{O}$ autor, assim, não reconhece os limites e condicionalidades que as condições materiais de existência impõem no desenvolvimento de um Estado nação, inserido no complexo de complexos. ${ }^{11}$

Ademais, na citação exposta, Paim (PAIM, 2007, p. 28) defende a ideia de que as supostas tendências brasileiras favoráveis ao socialismo devem ser compreendidas como problemas inerentes à inorganicidade, histórico-socialmente construída, na relação entre os sujeitos (mesquinhos) e Estado Nação (onipotente). Este problemático posicionamento em favor de uma organicidade harmoniosa entre sociedade civil e política caracteriza um lapso do filósofo baiano, ao passo que suprime princípios relativistas do culturalismo liberal em benefício de preceitos típicos das vertentes positivistas (tão criticadas pelo próprio Paim) - inclusive, neste ponto, existem

\footnotetext{
${ }^{8}$ Benjamin Constant (1836-1891) era membro do Partido Republicano e um dos principais difusores do positivismo no Brasil, sendo consagrado como fundador da República pela Constituição de 1891.

9 Joaquim de Fiori (1135-1202) foi um clérigo da Igreja Católica medieval que, defendendo o milenarismo e o advento da idade do Espírito Santo, acabou influenciando o desenvolvimento de vertentes filosóficas pautadas em suas formulações filosóficas.

${ }^{10} \mathrm{O}$ filósofo complementa que dada as características peculiares da sociedade brasileira, vislumbrou-se nas terras tupiniquins o desenvolvimento de uma perspectiva positivista que caminhava desvinculada da valorização do desenvolvimento científico das ciências naturais (PAIM, 2007, p. 90-91).

${ }^{11}$ Considera-se que, em decorrência do processo de divisão internacional do trabalho, a particularidade do modo de reprodução econômica de um determinado Estado nação determina, e condiciona, formas ideológicas específicas de compreensão da vida social e política (MARX; ENGELS, 2002 [1932]).
} 
concomitâncias entre os posicionamento filosófico-ideológicos de Antônio Paim (2007) e do general Golbery do Couto e Silva (2003). ${ }^{12}$

Apesar do lapso, o filósofo baiano retoma sua postura crítica em relação às heranças positivistas no pensamento político brasileiro, tecendo, inclusive, críticas as tendências militares de sobreposição ao direcionamento político-econômico do país. Segundo apresenta:

Somente com a abertura democrática das últimas décadas, criaram-se condições para a concepção e prática de um projeto luso-brasileiro, de amplitude crescente. Em tal circunstância incumbiria balancear a experiência pregressa. Nesta oportunidade, pretendo limitá-la ao que chamaria de primeiro momento tomando por base o livro O Brasil Mental (1898), em plena restauração da colaboração luso-brasileira que se fazia tomando ao positivismo como um dos elos de reaproximação.

Esta ocorre a partir dos anos setenta. Em Portugal é a época da chamada geração de 70, em cujo seio, no plano filosófico, Antero de Quental (1842/1891) seria talvez o mais destacado representante. Se bem certamente não fosse este o objetivo primordial - tanto que chegaram a considerar-se como os "vencidos da vida" -, aquele grupo promoveu notável renovação literária, tendo como máximo expoente a Eça de Queiroz (1845/1900). O fenômeno brasileiro chamou-se "surto de idéias novas" e desembocaria na ascensão e no domínio do positivismo no que restava do século XIX e em grande parte do seguinte, promovendo toda uma série de resultados negativos como $\mathrm{O}$ autoritarismo republicano, a ingerência militar na política e o empenho decidido em sufocar a meditação filosófica. Quanto a isto felizmente fracassaram, graças, entre outras coisas, à resistência iniciada pela Escola do Recife, acabando por florescer a crítica ao positivismo, emergindo daí múltiplas correntes no período contemporâneo (PAIM, 2007, p. 73-74 - grifos nossos).

Deste modo, Paim (2007) expressa elementos basilares de seu posicionamento político-ideológico, defendendo a construção de uma cultura política democrática que, a partir do florescimento de ideais filosóficos pluralistas, possibilite a superação das tendências autoritárias (herdadas do positivismo) na sociedade brasileira. Há de se considerar, no entanto, que sua percepção de desenvolvimento de uma filosofia que seja luso-brasileira compactua com elementos de reprodução de uma subjugação colonial do Brasil à Portugal - independente da existência, ou não, de uma relativa autonomia filosófica nacional, em relação à antiga metrópole, o pensamento brasileiro só se desenvolveria, robustamente, de forma interligada às principais contribuições

12 A percepção anticomunista de Golbery do Couto e Silva (2003) pautava-se na acusação do caráter egoísta dos sujeitos subversivos (comunistas/socialistas) que, supostamente, apropriavam-se destas perspectivas político-ideológicas exclusivamente para alçar-se no âmbito político, defendendo, também, a necessidade de construção de um Estado nação organicamente coeso e harmônico. 
contemporâneas da filosofia lusitana e pela própria superação de suas raízes. Assim, prossegue:

\begin{abstract}
A tarefa de superar o positivismo está inconclusa, sendo talvez mais aguda a situação brasileira que a portuguesa, porquanto o rebento principal dessa já longa tradição - o socialismo totalitário francamente inspirado na versão positivista do marxismo - dá provas de possuir maior fôlego no Brasil do que em Portugal. E dificilmente daremos cabo daquela tarefa, iniciada pelas gerações de Sampaio Bruno e Tobias Barreto sem estarmos atentos não só ao curso real de nossas culturas como igualmente à profunda e integral compreensão de seu substrato comum (PAIM, 2007, p.86).
\end{abstract}

Deste modo, no desenvolver das ideais em As Filosofias Nacionais, Antônio Paim (2007) gradualmente preocupa-se cada vez menos com os problemas inerentes à herança limitadora cristã e mais com o positivismo, que marcam geneticamente a formação das filosofias luso-brasileiras. Inclusive, não são tecidas críticas aos elementos religiosos presentes nas ideias de Eduardo Soveral ${ }^{13}$ e seu ideal de democracia cristã projeto político que preconiza uma relação harmônica entre o Estado nacional as demais instâncias da vida pública e privada, a partir do direcionamento de princípios morais cristãs em um sistema de poder dividido entre partidos liberais e sociais democratas (PAIM, 2007, p. 117-140).

Estabelecendo, portanto, como principal horizonte filosófico a superação das diretrizes positivista, que marcam profundamente a construção do pensamento filosófico nacional, Paim (2007, p. 174-176) indica como via de possibilidade as seguintes correntes de abordagem: neokantismo (de matriz culturalista, em especial a racionalização da religião de Hermann Cohen), neokantismo francês, fenomenologia, hegelianismo, espiritualismo, neotomismo e neopositivismo, excluindo dos parâmetros analíticos as vertentes marxistas, ${ }^{14}$ assim como de outras matrizes analíticas, que pautem-se na proposta de cientificismo.

Nota-se, então, que para o filósofo baiano existem duas principais grandes vertentes de correntes filosóficas que possibilitariam o desenvolvimento de uma

\footnotetext{
${ }^{13}$ Eduardo Silvério de Abranches de Soveral (1927-2003), foi um filósofo e diplomata português, tendo lecionado tanto em Portugal quanto no Brasil. Soveral compreendia a democracia cristã como a mais apta doutrina para elucidação dos desafios políticos contemporâneos.

14 Sobre os teóricos do marxismo, Paim (2007) ressalta a possibilidade de poder retornar a Eduard Bernstein para a superação do positivismo, ao passo em que este não tinha, em suas formulações, a pretensão de cientificidade - muito pelo contrário, o autor ocupou-se de criticar os elementos revolucionários inerentes ao pensamento marxiano, defendendo apenas as contribuições de Marx e Engels para a construção de um socialismo por vias democráticas e pacíficas.
} 
filosofia legitimamente luso-brasileira sendo elas as de matriz burguesa (neokantismos, fenomenologia, hegelianismo e neopositivismo) e as tradicionalistas (espiritualismo e neotomismo) - não deixando de considerar que há entre as vertentes filosóficas burguesas possibilidades de diálogo direto com os elementos tradicionalistas do cristianismo. Explicita-se, pois, seu posicionamento em favor da reprodução da ordem de dominação que, dadas as múltiplas vertentes burguesas passiveis de desenvolvimento filosófico-ideológico nacional, pode ou não pretender-se emancipada em relação à ordem político-econômica hegemônica internacional (que caracteriza o complexo de complexos capitalista).

Faz-se necessário, também, enfatizar que a tomada de posicionamento de Paim (2007), em combate as proposições filosóficas pautadas na cientificidade, incorre na compactuação com a difusão do princípio de dissolução da verdade, a partir do qual a relativização do real em prol das múltiplas formas de interpretação do mundo coíbem o desenvolvimento de teorias que pretendam apreender a realidade concreta em sua totalidade - partindo da perspectiva de Lukács (1970), a totalidade é passível de apreensão a partir do reconhecimento, desde a gênese, das múltiplas determinações que delineiam a particularidade do objeto de análise. Ressaltando, ainda, que:

Se é impossível a descoberta de um sentido no processo históricosocial, que possa ser racionalmente apreendido, instaura-se o império da incognoscibilidade com a relativização de todo conhecimento, permitindo uma multiplicidade inesgotável de interpretações, todas válidas. A realidade teria como característica essencial o seu caráter fragmentário, que impede qualquer possibilidade de síntese ou totalização, que apreenda o real. É, daí, que advém o jogo da crítica ao marxismo. O marxismo, ao contrário dessas outras concepções, reivindica para si a condição de pensamento totalizante $\mathrm{e}$ integralizador, reconhecendo-se como herdeiro e continuador das grandes sínteses do pensamento moderno. Mais: propõe-se a ser a expressão teórica do movimento dialético do real e que, por isso, é o único capaz de conhecer e explicar, racionalmente, a totalidade histórica. Então, é identificado pelos teóricos "pós-modernos" como um "paradigma" ultrapassado e preso a uma concepção determinista e teleológica da história (EVANGELISTA, 1992, p. 31).

Isto induz a problematizar a percepção que Antônio Paim (2007) exprime a respeito dos efeitos nocivos que, segundo o filósofo baiano, a retomada francesa ao niilismo, a partir da década de 1960, surtiu no desenvolvimento da filosofia ocidental conquistado a partir de uma suposta deturpação do sentido pleno "da negação 
nietzscheana dos valores fundantes da cultura ocidental" (PAIM, 2007, p. 62). Em suas próprias palavras:

O niilismo é, pois, a crítica das nossas tradições culturais, cuja irresponsabilidade reside precisamente em que se trata de nada colocar em seu lugar, deixando o vazio que transforma as pessoas em brutamontes irracionais, cujo potencial de violência gratuita expressou-se claramente na França, em 1968, deixando perplexa e chocada a população (PAIM, 2007, p. 62).

Apesar dos problemas relativos a defesa em favor de Friedrich Nietzsche, ${ }^{15}$ a percepção do filósofo baiano a respeito das tendências niilistas que passaram a integrar o desenvolvimento das ideias filosóficas, principalmente após a década de 1960, é assertiva e deveras relevante para a compreensão do atual estado de coisas, caracterizado pela escassez de proposições sólidas e amplamente articuladas de superação e emancipação humana - fenômeno decorrente de um longo projeto de estabelecimento do Estado de ideologia única, o qual atinge seu ápice com a derrocada da União das Repúblicas Socialistas Soviéticas (URSS) e a suposta vitória dos Estados Unidos da América (EUA) e de seu modelo político-econômico (MÉSZÁROS, 2014).

A década de 1960 constituiu, assim, um momento de virada para os paradigmas teórico-metodológicos das ciências sociais - acompanhada de uma transformação na forma de articulação político-social dos grupos organizados na vida social. Esta década se caracteriza, mais especificamente, como ponto crucial da "crise do marxismo", sendo que nela:

O aparecimento de novos movimentos sociais - estudantil, feminista, homossexual, ecológico, pacifista, entre outros - deslocou, para segundo plano, o "velho" movimento operário nas lutas por transformações sociais. Sugiram "novos sujeitos políticos", que questionaram não só a ordem social estabelecida como o conjunto de suas instituições, inclusive aquelas que ocuparam o papel de questioná-la, como os sindicatos e os partidos operários. O cotidiano passou a ser descoberto "enquanto espaço de reprodução da dominação ou de resistência contra ela", produzindo-se a "politização do social" e o "estilhaçamento da política". A "velha política" foi substituída pela "nova política". Esses "novos" movimentos sociais atacaram o "ponto fixo da política", cristalizado em instituições políticas bem delimitadas e que gravitava, exclusivamente, em torno do Estado. A estratégia de "tomada do poder" caducou e cedeu lugar à

\footnotetext{
${ }^{15}$ Em seu estudo da filosofia alemã, intitulado A Destruição da Razão, Lukács (1981) incumbiu-se de demonstrar a forma com as formulações nietzschianas conduzem o indivíduo imerso na sociedade capitalista à desembocar em duas únicas opções possíveis de futuro, sendo elas: o cinismo, acompanhado da fuga da insuportável realidade; ou o suicídio, neste caso, a ausência total de futuro concomitante com a percepção niilista do mundo.
} 
"contestação imediata e cotidiana de cada relação de dominação" (EVANGELISTA, 1992, p. 16).

Assim, o maio de 1968 consolidou um marco prejudicial para o desenvolvimento das concepções filosófico-ideológicas da esquerda mundial, ao passo em que preconizou o rompimento com as proposições anticapitalistas nas parcelas majoritárias da esquerda intelectual, nas diretrizes que passaram a dominar o sentido das produções filosóficas deste período:

\begin{abstract}
agora, trata-se de prioritariamente defender a ordem burguesa em nome da "liberdade", inclusive porque é ela que se mostra a mais adequada para o combate ao "totalitarismo" - leia-se: ao socialismo, não só identificado como a experiência soviética, mas como derivação necessária das ideias de Marx (PAULO NETTO, 2010, p. 253-254).
\end{abstract}

Retomando o posicionamento de classe assumido por Paim (2007), indica-se elementos ambíguos nas diretrizes político-ideológicas que permeiam suas formulações filosóficas. Por um lado, reconhece-se a assumida postura do intelectual baiano em defesa de uma perspectiva teórica culturalista de matriz liberal (portanto, de reprodução da ordem de dominação burguesa), à qual, contudo, esbarra em irreconhecimentos e limitações do relativismo inerente à esta vertente do pensamento. Desta forma, existe um outro lado de seu pensamento que, apesar das inúmeras críticas, flerta com raízes formativas do positivismo e do tradicionalismo - sendo que este último passa gradualmente a ser deixado de lado nas críticas que o autor desenvolve acerca das heranças filosóficas nocivas para a consolidação de uma sociedade democrático-liberal pautada no pluralismo de ideias.

Ademais, seu posicionamento liberal não se pretende emancipado das relações de subordinação brasileira com potencias europeias. Fato que se torna explicito com a proposição de uma formulação filosófica unificada entre Brasil e Portugal, mantendo, deste modo, uma relativa reprodução da subjugação de tipo colonial (agora exclusiva ao campo das ideias).

Cabe, neste momento, analisar a forma como o intelectual baiano compreende as condicionalidades e determinações que os processos de mudanças histórico-políticoeconômicas exercem no desenvolvimento, e transformação, das formulações filosóficoideológicas. 


\section{Condições materiais e a objetividade dos posicionamentos teleológicos}

Já na apresentação de Momentos Decisivos na História do Brasil, Antônio Ferreira Paim (2000) elucida sua pretensão de analisar os três principais momentos da história nacional que, por seu entendimento, permitiriam ao Brasil tornar-se uma grande potência político-econômica e que, contudo, foram direcionados de maneira frustrante, desencadeando processos opostos às potencialidades cabíveis. Segundo o filósofo baiano, seriam estes momentos:

O primeiro configura-se nos séculos iniciais quando escolhemos a pobreza e nos deixamos ultrapassar pelos Estados Unidos, depois de termos sido mais ricos.

O segundo no século XIX, quando optamos pela unidade nacional mas nos revelamos incapazes de consolidar o sistema representativo.

Finalmente, o terceiro, no século $\mathrm{XX}$, quando estruturamos em definitivo o Estado Patrimonial, recusando terminantemente $\mathrm{o}$ caminho da democracia representativa (PAIM, 2000, p. 4).

Já tendo explicitado o posicionamento de classe de Antônio Paim, em favor da reprodução da ordem de dominação burguesa, encontramos em sua avaliação destes três momentos históricos alguns elementos que nos permitem elucidar, mais precisamente, a vertente do pensamento conservador à qual se vincula. Note-se, pois, que Paim (2000) inicia sua proposta explicitando sua preocupação com o fato da não consolidação de um regime econômico-político de tendências liberal-democráticas na conjuntura nacional processo que se viabilizaria a partir da formação de uma burguesia nacionalista revolucionária autêntica.

A primeira parte de sua obra de análise histórica consiste em um debate a respeito da subjetividade e objetividade no método historiográfico, Paim (2000) defende a proposição de que o historiador, comprometido com seu ramo do conhecimento, deve reconhecer, apesar de seu sistema de valores, a atribuição de distinguir, coletar e preservar fatos autênticos que serão relevantes para as gerações futuras. Contudo, sua constante necessidade em expor críticas às vertentes marxistas da historiografia $\mathrm{o}$ induzem a cometer um erro crasso, ao protestar que os "marxistas que chegaram ao ponto de afirmar que não há fatos, mas interpretações" (PAIM, 2000, p. 11) - a célebre frase nietzschiana, que marca a gênese do processo de relativização da verdade, é 
atribuída às vertentes historiográficas do marxismo como tentativa de denúncia da suposta invalidade científica de suas produções. ${ }^{16}$

A partir da sua proposta de filosofia culturalista da história, Paim (2000) apresenta, sobre o primeiro momento histórico decisivo para o desenvolvimento econômico nacional, a defesa da tese de que as ações e diretrizes impostas pela Inquisição aos países lusófonos determinaram não somente a perseguição à uma parcela majoritária da burguesia açucareira brasileira (tendo em vista sua condição de novoscatólicos, recém convertidos do judaísmo) como também a valoração da pobreza em detrimento da atribuição de não-valor ao acúmulo de riquezas. ${ }^{17}$ No que tange ao Brasil, o autor afirma:

A Inquisição vota [sic] um ódio cego à riqueza, sendo a questão religiosa um simples pretexto para estrangulá-la e torná-la impossível. Muitos estudiosos acreditam que essa preferência por perseguir pessoas de posse adviria das rendas que em seguida auferiam pelo confisco de seus bens. Mas esta seria uma lógica primária já que atuavam no sentido de secar a mesma fonte de onde provinham. $\mathrm{O}$ mais provável é que se tratasse de ódio irracional ao lucro e à riqueza, como procuraremos demonstrar em seguida.

De sua ação no Brasil não resultou apenas o desmantelamento da indústria açucareira - impedindo-nos de nos mantermos ricos - mas sobretudo em ter logrado nos fossem inculcados valores contrários àquele enriquecimento (PAIM, 2000, p. 89).

Note-se, pois, uma concordância de Paim (2000) com a percepção weberiana das relações estabelecidas entre cultura, religião e economia na determinação das potencialidades de desenvolvimento das diversas e específicas sociedades. O filósofo baiano, chega até mesmo à indicar que os principais grupos brasileiros do período colonial que detinham potencial de fomentar um real desenvolvimento econômico no Brasil seriam, em primeiro plano, os judeus (convertidos legalmente ao catolicismo sem, contudo, abandonar suas convicções no âmbito da vida particular e econômica) e, em menor medida, os protestantes holandeses que tiveram protagonismo na vigência do governo de Mauricio de Nassau em terras nordestinas (1637-1643).

\footnotetext{
${ }^{16}$ Inclusive a inexistência da verdade é um dos princípios de irracionalidade que caracterizam o processo de destruição da razão apontado por Lukács (1981).

${ }^{17}$ Em decorrência disto, aproximadamente vinte porcento (20\%) da obra Momentos Decisivos na História do Brasil ocupa-se de discorrer sobre os conflitos religiosos que tomaram forma na Europa Ocidental a partir do século XV - abordando, de forma enfadonha, a problemática da relação estabelecida entre a Igreja Católica Romana e o poder do Estado, as vertentes protestantes do cristianismo, o judaísmo e os novos-católicos (PAIM, 2000, p. 47-84).
} 
Paim (2000) incorre, deste modo, em uma percepção teórica que exacerba o papel desempenhado pela religiosidade nas determinações da cultura nacional dos países de matriz lusófona, sem atentar-se a forma que as relações de produção majoritárias incorporam, e direcionam, o dinâmico desenvolvimento destas configurações das visões de mundo específicas destes países. É claro que não se pode excluir as contribuições do catolicismo na formação específica das ideologias lusófonas, contudo, é relevante, também, atentar-se as dimensões da forma como Portugal integrou, gradualmente, a divisão mundial do trabalho social. Deste modo, faz-se necessário enfatizar que a exclusão das determinações que levaram tanto a consolidação e vigência do Tratado de Methuen (1703-1836), quanto suas repercussões nas relações lusitanas com a França durante o império de Napoleão Bonaparte (1804-1815), é mesmo que ignorar um dos elementos mais relevantes da formação cultural lusófona (seu lugar de produção no complexo de complexos) - considerando, ainda, que "[...] a evasão diante dos dilemas histórico-sociais mais decisivos é um traço peculiar ao pensamento decadente" (PAULO NETTO, 2010, p. 243). Ademais, o filósofo baiano afirma que:

\begin{abstract}
Essa aversão ao lucro e à riqueza deixou marcas profundas em nossa cultura e trouxe algumas conseqüências de que não conseguimos até hoje nos livrar. Entre estas sobressai a pouca valorização dos empresários (e da própria empresa privada) que responde pela oferta fundamental do emprego, mesmo numa economia com os níveis de estatização alcançados pela brasileira. E o emprego se situa entre os bens maiores da sociedade moderna. Sem emprego, vale dizer, sem remuneração, a pessoa está privada de ter acesso ao que a economia desenvolvida proporciona à maioria. Tanto isto é verdade que, naquelas economias, o desemprego é objeto de políticas públicas específicas, sendo a sua medida um dos indicadores do bem estar social (PAIM, 2000, p. 92).
\end{abstract}

No que se refere ao entendimento acerca da primeira etapa decisiva da história brasileira, Paim (2000, pp. 107-108) indica a construção e difusão de duas principais tradições culturais herdadas de Portugal, a moral contra-reformista (com ênfase às diretrizes persecutórias e normativas da Inquisição) e o cientificismo (difundido nas terras lusófonas por meio das reformas pombalinas), sendo que a primeira se sobrepôs à segunda, tendo como consequência, para o Brasil, um retardo na difusão em maior amplitude dos ideais vinculados ao liberalismo econômico - que só alcançaram grandes proporções nacionais no decorrer do século XIX, sendo subsequentemente sufocadas pela República, que em combate à vertente de pensamento liberal, teria ressuscitado "as 
velhas tradições caracterizadas precedentemente: a valorização contra-reformista, o patrimonialismo e o cientificismo" (PAIM, 2000, p. 128).

Chega-se, então, ao segundo momento decisivo da história brasileira, Paim (2000, p. 110-133) aborda a incapacidade que os governos consolidados nas terras brasileiras, desde a chegada da corte portuguesa (1808) até a Proclamação da República (1889), apresentaram no que tange ao processo de integração nacional do amplo território pertinente ao país. Para tanto, são abordados os principais movimentos separatistas que tomaram forma no decorrer do século XIX em terras tupiniquins, exaltando a ascensão e lastimando o declínio dos ideais liberais na conjuntura nacional do período.

O filósofo baiano, então, tece sua análise sem apresentar ponderações sobre as configurações econômicas que caracterizavam a divisão nacional do trabalho, hierarquizando o poderio hegemônico das distintas regiões do país no período e suas potencialidades de universalização político-ideológica em prol da mobilização de forças para implantação de uma real revolução liberal, ignorando, portanto, a forma como as condições materiais da vida social perpassam o processo de crivo da vitória, ou não, de uma determinada posição teleológica secundária - fato é que, inexoravelmente, uma interação entre causalidades e objetivações apresenta-se como determinante na disputa de posições no modelo de dominação vigente (possibilitando a manutenção, reformulação ou destruição deste).

Deste modo, enfocando-se neste segundo momento histórico, Paim (2000) dirige suas críticas principalmente para o caráter patrimonialista de gerência das instituições públicas e para as relações de harmonia e atritos que se desenvolveram entre o Estado e os membros do clero católico. Segundo o filósofo baiano, a recusa de absorção dos líderes militares (fortalecidos politicamente pela Guerra do Paraguai) no sistema patrimonialista de representação política e as desavenças com setores específicos da hierarquia católica nacional (ambos decorrentes das tendências liberais de direcionamento político do Segundo Reinado), são elementos que possibilitam compreender o processo que culminou na decadência da Monarquia e na Proclamação da República - fato histórico entendido por Paim (2000) como extremamente nocivo, ao passo em que considera o Segundo Reinado (1840-1889) enquanto período de construção do que poderia consolidar-se como Estado Liberal de Direito no Brasil. 
Assim, o filósofo baiano, indicará que o período da República Velha (18891930) será marcado tanto pela exacerbação do modelo patrimonialista de Estado quanto pela acentuação dos problemas políticos decorrentes da insistência no processo de centralização do poder, ao passo em que as distintas configurações do amplo espaço geográfico nacional dificultavam o delineamento de um projeto político-econômico unificado, gerando, ao contrário, grupos de oposição que representavam os ideais de desenvolvimento específicos de suas regiões, competindo entre si para conquistar o direcionamento das políticas de Estado (PAIM, 2000, p. 153-155). No que tange a este processo de ocupação patrimonialista do Estado, o filósofo baiano indica que

Havia na Europa regiões em que o Estado não se deparou pela frente com nenhum grupo social economicamente poderoso e formou-se como um poder incontestável. A esses denominou-se de Estado Patrimonial. Tal era a circunstância da Península Ibérica (Espanha e Portugal) e também da Prússia (PAIM, 2000, p. 154).

Esta lógica racionalista formal de apreensão do desenvolvimento históricopolítico-econômico dos Estados-nação, que ignora as condições materiais que possibilitariam a ascenção de burguesias revolucionarias no contexto de transição ocidental para o capitalismo, exprime-se mais uma vez. Sem atentar-se nem aos modos específicos que as potencias capitalistas tardias encontraram para consolidar-se na divisão internacional do trabalho (via prussiana) e nem as particularidades das relações de dominação colonial específica dos países ibéricos, Paim (2000) parte do princípio de que surgimento de uma burguesia revolucionária estava condicionado apenas as potencialidades das ideias burguesas da uma classe economicamente hegemônica no Estado nação, sem atentar-se as causalidades impostas e a própria configuração internacional de disputas pela hegemonia político-econômica. Em continuação à sua análise sobre o patrimonialismo, afirma que:

Desde os anos oitenta, entretanto, aparecem plenamente as conseqüências dessa dominação da economia pelo Estado. Ao contrário dos países capitalistas desenvolvidos, onde foi alcançada uma distribuição de renda relativamente equilibrada, a camada que ascendeu ao bem estar material revelou-se muito reduzida. A imensa maioria permaneceu pobre. E como ocorreu colossal deslocamento do campo para a cidade, formaram-se em grande parte do território bolsões de miséria absoluta.

Como a tradição cultural mais vigorosa do país é eminentemente anticapitalista e, desde os anos trinta, essa tradição passa a assumir abertamente feição socialista, atribuíram-se ao capitalismo os males do nosso desenvolvimento. A verdade, entretanto, é que não há país 
capitalista onde o Estado detenha $70 \%$ da economia, como se dá no Brasil (PAIM, 2000, p. 152).

Sua lógica de raciocínio e sua vendeta anticomunista, mais uma vez, o direcionam para interpretações equivocadas acerca da particularidade da via de desenvolvimento capitalista brasileira (à qual o autor chega a indicar como potencialmente inexistente). A alta concentração de renda e poder que decorreu do modelo específico de reprodução capitalista na realidade brasileira é indicada pelo filósofo baiano como decorrente de um suposto socialismo vigente no direcionamento político-econômico nacional desde a ascenção do trabalhismo de Getúlio Vargas (19301945) - as propensões nacionais desenvolvimentistas de Vargas são, assim, classificadas como socialistas pelo fato de pautarem-se no protagonismo do Estado para o fomento do desenvolvimento econômico. Deste modo, em continuidade de sua defesa de consolidação de uma democracia liberal legitima na realidade brasileira, e das reflexões dos momentos históricos que à inviabilizaram, o filósofo baiano pondera que:

Os militares têm uma atuação abertamente política. Muitos deles tornar-se-iam interventores estaduais e formariam com Vargas, na medida em que as opções se foram definindo. Os que não ascenderam ao poder constituíram uma agremiação denominada Club 3 de outubro, cuja pregação assume progressivamente conotação socialista. Com o desenrolar da situação, dividem-se em dois grupos: o primeiro adere à Ação Integralista Brasileira, que tinha uma proposta fascista e, o segundo, à Aliança Nacional Libertadora, que era uma organização sustentada pelo Partido Comunista. Esta promoveria em novembro de 1935 uma rebelião militar, de que se valeu Vargas para fechá-la. Os integralistas pareciam apoiar Vargas na medida em que este marchava para instaurar no país uma ditadura. Mas acabaram rompendo (PAIM, 2000, p. 156).

Esta mesma lógica perniciosa de difusão de um conhecimento que tenta, de forma dissimulada, vincular os regimes nazi-fascistas ao socialismo está presente tanto na obra As Filosofias Nacionais (PAIM, 2007, p. 158-159) quanto em Liberdade Acadêmica e Opção Totalitária, sendo que nesta última o autor afirma que "o sistema totalitário é uma criação deste século. Simbolizam-no as doutrinas do stalinismo e do nazismo e as personalidades de Stalin e Hitler" (PAIM, 1979, p. 197). Pertinente se faz, indicar que as mencionadas ideias, que buscam classificar o nazi-facismo como regime de caráter socialista, têm sido veiculadas em redes sociais e canais de comunicação por intelectuais públicos que representam o conservadorismo contemporâneo (dos quais se destaca Olavo de Carvalho) - isto gerou um episódio risível de âmbito internacional no 
ano de 2018, quando a própria embaixada alemã viu-se obrigada à posicionar-se frente à setores da sociedade brasileira que insistiam, de modo a-histórico, em defender a vinculação dos regimes totalitários de vertente fascista ao socialismo/comunismo.

A insistência do filósofo baiano em vincular regimes totalitários às proposições inerentes às teorias marxistas beira o ridículo quando este busca denunciar supostas tendências socialistas no direcionamento político-econômico da ditadura militar brasileira (1964-1985) - regime político que, muito pelo contrário, se impôs em prol do combate as supostas ameaças comunistas/socialistas que tomavam forma em decorrência do governo de João Goulart (1961-1964). Assim, no que se refere à construção das industrias de base estatais do período, o autor afirma que "o predomínio do Estado deveu-se à ascendência alcançada pela facção militar que se deixou encantar pela sereia socialista e nutria notórios sentimentos anti-capitalistas" (PAIM, 2000, p. 160).

A tônica das reflexões de Paim (2000) a respeito da realidade política brasileira o direciona para uma fundamentação pautada no que Coutinho (2010) classifica como "miséria da razão". Apropriando-se de elementos específicos dos momentos históricos e dos direcionamentos político-econômicos brasileiros (recusando-se a apreender a totalidade dos processos) o filósofo baiano busca classificar todos os regimes políticos que baseiam-se na construção de um Estado forte como partidários dos princípios socialistas. Este processo de racionalismo miserável, é claro, está diretamente relacionado com seu posicionamento de classe e com a objetividade político-ideológica de suas formulações filosóficas.

Chega-se, então, à última etapa da análise do pensamento conservador de Antônio Paim, sendo que já na obra Momentos Decisivos na História do Brasil (2000), o intelectual baiano traz os indícios das pretensões de sua objetividade ideológica no âmbito do direcionamento econômico nacional. Analisando a situação do Brasil na década de 1990 o autor afirma que no momento em questão "a privatização representaria significativa contribuição, tema que merece ser considerado se queremos compreender as dificuldades que se interpõem à eliminação do Estado Patrimonial" (PAIM, 2000, p. 204). Neste sentido, vale ressaltar o papel desempenhado pela proposição de privatização das estatais que marcaram os governos de Fernando Collor (1990-1992) à Fernando Henrique Cardoso (1995-2003) e que, independente do retorno 
do investimento nas estatais, não vivenciou um retrocesso nos governos de Luís Inácio Lula da Silva (2003-2011) e Dilma Rousseff (2011-2016). ${ }^{18}$

Não se pode deixar de ponderar, também, que o processo de privatização das estatais brasileiras favoreceu majoritariamente o capital internacional em detrimento do nacional - fato que se exacerba pela debilidade da burguesia interna, culminando na gradual desindustrialização brasileira. Independente destes acontecimentos, a eleição 2018 para a presidência da República foi marcada pela primazia do apoio popular em oposição as tendências assistencialistas implementadas pelos governos do Partido dos Trabalhadores (PT) e à própria continuidade das empresas de caráter estatais do Brasil características que remetem ao mencionado Estado forte, indicado por Paim (2000) como vinculado a proposições socialistas.

Marcado por um exacerbado e anacrônico anticomunismo, os primeiros meses de governo de Jair Bolsonaro (2019) têm se destacado pela implementação de um projeto neoliberal de direcionamento econômico do Estado, aparentando as ambições de extinção das funções assistencialistas do Estado, das empresas estatais, do desenvolvimento econômico sustentável e propensões ao acirramento do caráter subordinado da economia nacional em relação as grandes potencias capitalistas (com ênfase para os EUA).

Destaca-se, assim, a forma como as análises da filosofia culturalista da história de Antônio Ferreira Paim (2000), contribuíram para a construção de uma percepção político-ideológica de aprofundamento do caráter subjugado do capitalismo nacional em determinados setores liberais da sociedade brasileira. Tendo evidenciado esse elemento econômico de seu pensamento resta, pois, analisar a objetividade de suas formulações filosóficas no que tange ao direcionamento das relações políticas na realidade brasileira.

\section{Elementos do projeto de porvir no culturalismo liberal brasileiro}

A última obra seleciona, de modo intencional, para compreensão do cerne político-ideológico das contribuições filosóficas de Antônio Ferreira Paim. O livro Liberdade Acadêmica e Opção Totalitária, consiste em uma coletânea de trabalhos organizada pelo próprio filósofo baiano, na qual ele contribuiu com três textos,

18 Conforme apresenta Deo (2011), o governo Lula (Partido dos Trabalhadores) foi marcado pela reafirmação do caráter privatista do Estado, implementando medidas que favorecessem o estabelecimento de parcerias público-privadas. 
acrescidos da introdução e duas cartas de sua autoria. Sendo necessário enfatizar que a mencionada obra foi originalmente publicada no ano de 1979, em plena ditadura militar brasileira (1964-1985).

Já na introdução, Paim (1979, p. 04-20), expõe os motivos que levaram a organização da obra, indicando o acontecimento da censura imposta pelo Departamento de Filosofia da Pontifícia Universidade Católica do Rio de Janeiro (PUC-RJ) à um texto da autoria de Miguel Reale ${ }^{19}$ que deveria compor o material didático da disciplina História do Pensamento. ${ }^{20}$ Segundo a percepção do autor, e dos contribuidores da coletânea, o posicionamento da PUC-RJ decorreu de uma suposta tomada de posição em defesa do totalitarismo filosófico-ideológico de vertente, portanto, marxista - a qual estaria dominando setores universitários e católicos no Brasil.

Antes de prosseguir as análises, é relevante atentar à determinados elementos presentes na carta enviada por Antônio Paim (26 de março de 1979, p. 221-223) ao, então reitor da PUC-RJ, padre João Mac Dowell ${ }^{21}$ (1976-1984). Na carta, o filósofo baiano reforça seu pedido de desvinculação do Programa de Filosofia da PUC-RJ, afirmando que nos dez anos que compôs o corpo discente (1969-1979) foram marcados pela possibilidade de amplo desenvolvimento de sua corrente de pesquisa filosófica, lamentando, a intolerância que se instaurou em 1979 no direcionamento político de esquerda da instituição que, em suas palavras, "não aderiu à plataforma liberal do Estado de direito por uma conversão democrática mas por acreditar que, nas novas condições, mais fácil lhe seria impor uma opção totalitária” (PAIM, 1979, p. 223).

As ponderações lamuriosas feitas por Paim (1979, p. 221-223) ao padre João Mac Dowell parecem ignorar a realidade universitária que permaneceu vigente durante

\footnotetext{
${ }^{19}$ Miguel Reale (1910-2006), foi jurista, político e filósofo, tendo destaque nas articulações históricas de processos conservadores brasileiros, foi um dos ideólogos protagonistas da Ação Integralista Brasileira (AIB) e um dos principais redatores da Ementa Constitucional no 1 (1969). Demonstra-se, assim, O vínculo de Reale com os grupos de tendências fascistas da década de 1930 (AIB) e subsequentemente, com a linha mais rígida dos setores militares que articularam a ditadura militar brasileira - período de vigência dos governos de Arthur da Costa e Silva (1967-1969) e Emílio Garrastazu Médici (1969-1974). ${ }^{20} \mathrm{O}$ texto censurado, intitulado Filosofia como Autoconsciência de um Povo, da autoria de Miguel Reale encontra-se disponível nos anexos da obra (In: PAIM, 1979, p. 224-248). Nele, o autor tece críticas às tendências totalitárias e unitárias de determinadas correntes filosóficas, políticas e religiosas, conclamando a sociedade brasileira à romper com o academicismo e com as influências acríticas de contribuições externas para a formulação de uma filosofia realmente nacional. Ao mesmo tempo em que os marxismos de vertentes stalinista e economicistas são criticados outras vertentes mais relativistas das relações entre infraestrutura e superestrutura do marxismo são considerados como válidos para o profícuo debate de ideias no Brasil.

${ }^{21}$ Nascido em Belém do Pará no ano de 1934, João Augusto Anchieta Amazonas Mac Dowell destacouse por sua carreira acadêmica dentro da Igreja Católica, fazendo parte da Comissão de Reintegração dos Professores Cassados pelo AI-5 do MEC (1979-1980).
} 
seus anos dourados de atuação na PUC-RJ (1969-1979) - período marcado pela forte perseguição e repressão dos intelectuais vinculados as vertentes progressistas do pensamento político-econômico, tanto socialistas/comunistas (Ruy Mauro Marini, Teotônio dos Santos, Vânia Bambirra, Florestan Fernandes, entre outros) quanto liberais (Raymundo Faoro, Celso Furtado, entre outros). A isto, acrescem-se apontamentos realizados pelo autor na já citada introdução da obra, segundo ele:

\begin{abstract}
A questão de como enfrentar os comunistas e grupos afins, no plano político, embora diga respeito à plena configuração do projeto de convivência democrática que devemos conceber e implantar, não se apresenta dessa forma para o debate acadêmico suscitado pela censura ao texto do prof. Miguel Reale. Qualquer que seja a solução política do problema - cuja questão nuclear é a permissão ou não da existência legal do Partido Comunista - ao nível da Universidade o tema assume conotação diversa (PAIM, 1979, p. 12).
\end{abstract}

Assim, escusando-se de abordar o âmbito político da questão, Paim (1979) afirma a pretensão de manter o enfoque da obra na forma como os intelectuais liberais devem delinear suas propostas de atuação em combate as proposições marxistas de tendências totalitárias - já nesta obra, tanto Paim quanto Miguel Reale apresentam concordância com a possibilidade de convivência com específicas vertentes intelectuais do marxismo nas configurações de uma sociedade democrática (desde que estas estejam pré-dispostas à pautar-se em uma perspectiva social democrata), conforme já indicado na obra As Filosofias Nacionais (2007). Exprimem-se, portanto, elementos políticoideológicos que tendem a direcionar uma perspectiva de sociedade política que se construa nos moldes estado-unidenses, nos quais Republicanos (conservadores) e Democratas (progressistas) transitam, quase que exclusivamente, em uma oposição controlada de perspectivas liberais pouco distintas.

No capítulo As Raízes da Crise na PUC, Paim (1979, p. 167-175) busca traçar a linhagem do pensamento filosófico que delineou as configurações da suposta "crise da PUC”. Para tanto, o filósofo baiano insiste em estabelecer paralelos entre as heranças positivistas brasileiras e a forma como o marxismo se consolidou, históricosocialmente, na realidade brasileira. Retomando as formulações filosóficas do padre Lima Vaz ${ }^{22}$ (1921-2002), Paim (1979) ambiciona denunciar o modo como a vertente

\footnotetext{
22 Henrique Claúdio de Lima Vaz (1921-2002), foi um padre jesuíta, vinculado à Teologia da Libertação, que se destacou pela elaboração de uma crítica filosófica ao reducionismo nas vertentes teóricas do marxismo (a partir da retomada de Hegel para compreensão de Marx), visando uma articulação políticosocial que se concretizou em setores da Ação Popular e na Juventude Universitária Católica (JUC).
} 
brasileira do clero libertador (em decorrência da herança nacional às predisposições totalitárias) partilha de ideais socialistas contrários aos princípios democráticos.

Concomitante com a perspectiva anticomunista que caracterizou o período de Guerra Fria (1947-1991), Paim (1979) constrói a percepção de um suposto aparelhamento das Universidades nacionais (com destaque para a PUC-RJ) por parte dos comunistas de tendências marxistas-positivistas. Assim, conclama a comunidade acadêmica a reconhecer-se enquanto a única instância capaz de enfrentar os grupos totalitários na realidade brasileira, ao passo que "a Nação optou, de forma insofismável, pelos riscos da democracia” (PAIM, 1979, p. 167). O filósofo baiano, de modo descomedido, chega a comparar a censura imposta ao texto de Miguel Reale com os "autos de fé” da Inquisição, deste modo, enfatiza que:

O grande desafio que temos pela frente, na etapa de evolução política em que ingressamos, consiste em obrigar os segmentos totalitários da sociedade a expor seus pontos de vista e a discuti-los de forma civilizada, sem nos deixarmos envolver pelos seus métodos inquisitoriais, que, se puderam vicejar à sombra do sistema autoritário, dificilmente sobreviverão no Estado de Direito (PAIM, 1979, p. 174).

Note-se, pois, os exageros cometidos pelo autor em relação à uma ocorrência tão comum aos setores da esquerda no seu mencionado período profícuo de desenvolvimentos das pesquisas de sua linha culturalista (1969-1979). Determinada percepção remete à sensação de insegurança que estes intelectuais conservadores passaram a sentir em decorrência da reintegração dos intelectuais da esquerda, uma perspectiva que:

Conserva-se como puro "sentimento", isto é, como reação espontânea e sentimental diante da aparência dos processos reais. $\mathrm{O}$ "sentimento do mundo", por isso, confunde-se com a experiência vivida, subjetiva, dos estratos intelectuais, funcionando como mais um limite espontâneo à correta apreensão da objetividade.

Verifica-se assim, no que toca a esses "sentimentos do mundo", a mesma duplicidade que antes constatamos no plano puramente filosófico. De acordo com o período histórico, os intelectuais podem experimentar, diante do real, uma sensação de "angústia" ou uma sensação de "segurança", e, de acordo com isso, elaborarão posições filosóficas preponderantemente irracionalistas ou pseudorracionalistas (COUTINHO, 2010, p. 62).

Dando continuidade à sua reflexão, o capítulo Os Fundamentos HistóricoCulturais da Opção Totalitária no Brasil (PAIM, 1979, p. 175-181) consiste na culpabilização direta dos membros vinculados à Teologia da Libertação sobre um 
suposto processo de perseguição dos intelectuais da PUC-RJ em decorrência de posicionamentos político-ideológicos divergentes do denominado radicalismo totalitário socialista. Mais uma vez, Paim (1979) insiste em ignorar fatos históricos que fundamentariam uma percepção ampla da conjuntura social, neste caso em específico, o filosofo baiano não demonstra preocupação em evidenciar o papel desempenhado pelos setores libertadores do clero brasileiro no que tange à pressão para redemocratização da sociedade brasileira, nem mesmo em considerar as perseguições que foram impostas à esta vertente do clero em decorrência de seu posicionamento frente à ditadura militar brasileira - censura, perseguição política, torturas, entre outros (LÖWY, 2000).

Sua última contribuição para a obra, o capítulo As Formas de Opção Totalitária no Brasil (PAIM, 1979, p. 196-203), traz a seguinte ponderação:

Nesta nova tentativa de estruturar a convivência democrática, os liberais devem assumir diretamente a responsabilidade de mostrar que a opção totalitária não é a alternativa legítima para o autoritarismo. A esquerda totalitária, na verdade, age em conluio com as alas extremadas do autoritarismo (PAIM, 1979, p. 197).

Assim, o filósofo baiano segue sua reflexão retomando à crítica as ideias do teólogo da libertação padre Lima Vaz e as diretrizes históricas que nortearam, em sua análise, o direcionamento das ações políticas do Partido Comunista Brasileiro (PCB), sem considerar, em nenhum momento, a multiplicidade de vertentes que permeou a Teologia da Libertação brasileira, tanto liberais quanto socialistas, (NEVES JR, 2016) e nem as propensões do PCB em articular-se, periodicamente, com setores da burguesia liberal para o direcionamento político que garantisse o desenvolvimento industrial, entendido como etapa essencial para a futura concretização de uma Revolução Socialista (MAZZEO, 1999), reforçando, mais uma vez, sua lógica miserável de racionalidade. Por fim, o filosofo baiano conclui sua reflexão com a seguinte indicação:

A democracia representativa, desde que apoiada num sistema eleitoral que aproxime o representante do representado e minimize as distorções inevitáveis, pode perfeitamente absorver a ação de agrupamentos totalitários. Basta que não se lhes dê trégua no plano doutrinário, obrigando seus ideólogos a descer do pedestal, em que preferem ficar encastelados, para enfrentar a crítica dos que deles discordam, não temem o ataque pessoal e não se disponham a lhes fazer concessões nesse terreno, baixando ao mesmo nível. Sobretudo obrigando-os a disputar votos para dispor de uma representação mais preocupada em fazer-se identificar por posições claras e explícitas que se camuflar por trás de princípios gerais. O sistema representativo não pode entretanto tolerar o totalitarisamo [sic]. Não pode haver 
ambigüidade na condenação dessa modalidade de ação política, em face da discordância com os métodos empregados em seu combate, no mais recente ciclo do autoritarismo. $\mathrm{O}$ pensamento liberal não teme enredar-se em semelhante teia, reconhecendo a necessidade de instrumentos legais eficazes e aptos a conjurar semelhante ameaça (PAIM, 1979, p. 203).

Deste modo, a objetividade política que se expressa nas contribuições de Antônio Paim (1979) é de limitar a atuação de intelectuais da esquerda nacional ao campo do debate de ideias em nível intelectual. Contradizendo sua proposta introdutória, o filósofo baiano conclama a institucionalização de mecanismo legais que previnam a ascensão política de vertentes propensas a perspectivas da esquerda marxista (que não se adequem à proposição da social democracia). Suas proposições analíticas podem, assim, ser entendidas como o germe do anticomunismo brasileiro contemporâneo, que vislumbra em qualquer tendência progressista do campo político uma vinculação ao socialismo/comunismo - mesmo que estes se proponham à defesa de pautas democráticas caras à coexistência de uma sociedade plural (como o identitarismo e a diminuição da exacerbada desigualdade social que caracteriza a realidade nacional).

\section{Considerações finais}

O presente trabalho teve por intuito analisar o pensamento político de Antônio Ferreira Paim, entendo-o como um dos principais ideólogos do conservadorismo brasileiro contemporâneo. Ambicionou-se apreender, a partir do materialismo históricodialético de matriz lukácsiana, o posicionamento de classe assumido pelo intelectual baiano e as implicações de suas formulações filosófico-ideológicas para as configurações dos conflitos de classe na realidade brasileira. Para tanto, foram selecionadas, de maneira intencional, três obras do autor: As Filosofias Nacionais (2007), Momentos Decisivos da História do Brasil (2000) e Liberdade Acadêmica e Opção Totalitária (1979).

A primeira parte da pesquisa ocupou-se de analisar os elementos basilares da perspectiva culturalista liberal de Antônio Paim (2007), evidenciando seu posicionamento em favor da manutenção, e reprodução, de uma ordem burguesa que favorece a continuidade da relação de subjugação do Brasil frente às potencias capitalistas hegemônicas. Indicou-se, ainda, as ambiguidades de suas críticas às vertentes filosóficas positivista e tradicionalista - que em determinados momentos são 
apropriadas nas formulações filosófico-ideológicas do autor, ao passo em que são consideradas elementos intrínsecos do pensamento brasileiro que necessitam, em certa medida, ser superados.

O segundo momento do trabalho identificou a lógica racionalista formal (razão miserável) utilizada por Paim (2000) para analisar os momentos históricos que considera decisivo para o desenvolvimento do Brasil tal como se construiu. Demonstrou-se a preocupação do filósofo baiano em defender a construção de um Estado liberal organicamente coeso com uma sociedade pluralista que, contudo, deveria perpassar limites político-ideológicos. Denunciou-se, ainda, a maneira perniciosa como o autor deturpou a classificação de modelos de Estados, igualando proposições de extrema-direita com as da esquerda marxista, de modo a possibilitar a fundamentação das objetividades econômicas (privatizações) que perpassam sua posição ideológica.

A terceira, e última, parte do trabalho preocupou-se em classificar a objetividade político-ideológica que embasa a filosofia de Antônio Paim (1979), indicando o modo como sua racionalidade formal alicerça uma proposição pedante de perseguição às proposições de esquerda, conclamando o auxilio das vertentes liberais para restringir à atuação destes setores progressistas ao âmbito acadêmico.

Por fim, cabe a pesquisa reconhecer as limitações impostas às análises apresentadas - principalmente no que tange a amplitude da produção bibliográfica de Antônio Paim. Reforça-se, assim, a proposta de incentivar novas pesquisas que se disponham a compreender criticamente as formulações filosófico-ideológicas do conservadorismo nacional, que se encontra em visível ascensão na sociedade civil brasileira contemporânea.

\section{Referências Bibliográficas}

COUTINHO, Carlos Nelson. O Estruturalismo e a Miséria da Razão. $2^{\mathrm{a}}$ ed. São Paulo: Expressão Popular, 2010.

CZAJKA, Rodrigo. Praticando delitos, formando opinião: intelectuais, comunismo e repressão no Brasil (1958-1968). Tese de Doutorado em Sociologia. Campinas: Universidade Estadual de Campinas (Unicamp), 2009.

DEO, Anderson. A Consolidação da Social Democracia no Brasil: forma tardia de dominação burguesa nos marcos do capitalismo de extração prussiano-colonial. Tese de Doutorado em Ciências Sociais. Marília: Universidade Estadual de São Paulo (Unesp), 2011.

EVANGELISTA, João E. Crise do marxismo e irracionalismo pós-moderno. São Paulo: Editora Cortez, 1992. 
LÖWY, Michael. A Guerra dos Deuses: Religião e Política na América Latina. Petrópolis: Editora Vozes, 2000.

LÖWY, Michael. Conservadorismo e extrema-direita na Europa e no Brasil. Serviço Social e Sociedade, São Paulo, n. 124, p. 652-664, dezembro de 2015.

LUKÁCS, Georg. Introdução a uma estética marxista: sobre a particularidade como categoria estética. $2^{a}$ ed. Rio de Janeiro: Civilização Brasileira, 1970.

LUKÁCS, Georg. The destruction of reason. Whitstable: Whitstable Litho Ltd, 1981.

LUKÁCS, Georg. Para a ontologia do ser social. volume 14. Maceió: Coletivo Veredas, 2018.

MARX, Karl; ENGELS, Friedrich. Ideologia Alemã. 2a ed. São Paulo: Martins Fontes, 2002.

MAZZEO, Antônio C. Sinfonia Inacabada: a política dos comunistas no Brasil. São Paulo: Boitempo Editorial, 1999.

MÉSZÁROS, István. O poder da ideologia. São Paulo: Boitempo Editorial, 2014.

NEVES JR, José W. A. Novas fontes para compreender a censura prévia militar: uma análise do arquivo censurado do jornal católico O São Paulo (1972-1978). Dissertação de Mestrado em Ciências Sociais. Londrina: Universidade Estadual de Londrina (UEL), 2016.

PAIM, Antônio F. Liberdade Acadêmica e Opção Totalitária: um debate memorável. Rio de Janeiro: Editora Arte Nova, 1979.

PAIM, Antônio F. Momentos decisivos da História do Brasil. São Paulo: Martins Fontes, 2000.

PAIM, Antônio F. As Filosofias Nacionais. $3^{\text {a }}$ edição revisada e ampliada. Londrina: Instituto de Humanidades, 2007.

PAULO NETTO, José. Posfácio. In: COUTINHO, Carlos Nelson. O Estruturalismo e a Miséria da Razão. $2^{a}$ ed. São Paulo: Expressão Popular, 2010.

SILVA, Golbery do Couto e. Geopolítica e Poder. Rio de Janeiro: UniverCidade, 2003. 